\title{
A GREY HYBRID MODEL TO SELECT THE OPTIMAL THIRD-PARTY LOGISTICS PROVIDER
}

\author{
A. Ulutaș ${ }^{*}$
}

\section{ARTICLE INFO}

Article details

Submitted by authors 20 Feb 2019

Accepted for publication 29 Mar 2021

Available online 28 May 2021

\section{Contact details}

Corresponding author

aulutas@cumhuriyet.edu.tr

\section{Author affiliations}

1 International Trade and Logistics Department, Cumhuriyet

University, Sivas, Turkey

\section{ORCID® identifiers}

A. Ulutaș

https://orcid.org/0000-0002-8130-1301

DOI

http://dx.doi.org/10.7166/32-1-2126
ABSTRACT

Enterprises need to work with a proper third-party logistics provider to reduce costs and increase their logistics performance; so the third-party logistics (3PL) provider selection problem is a significant one for them. In this study, grey step-wise weight assessment ratio analysis (SWARA) and grey combinative distance-based assessment (CODAS) are proposed to address this problem. To the best of the authors' knowledge, no other study uses grey SWARA and grey CODAS together to solve any problem. Therefore a new grey hybrid model incorporating grey SWARA and grey CODAS is proposed to identify the best 3PL provider.

\section{OPSOMMING}

Ondernemings is genoodsaak om 'n betroubare logistieke diensverskaffer te gebruik om onkostes te verminder en hul logistieke vertoning te verbeter. Die kies van 'n logistieke diensverskaffer is dus baie belangrik. Hierdie studie gebruik ' $n$ grys, stapsgewys geweegde verhoudingsanalise en grys gekombineerde afstandgebaseerde assessering om dié probleem aan te spreek. Die kombinasie van hierdie twee strategieë is die eerste van sy soort. ' $n$ Nuwe hibriede model wat die twee benaderings inkorporeer word dus voorgestel om die beste derde party logistieke diensverskaffer te identifiseer.

In an environment in which global competition is intense, businesses need to benefit from every positive opportunity to improve their performance. In this environment, strong competition and customer satisfaction push enterprises to work in close cooperation with external collaborators. Effective close partnerships with external partners enable companies to gain a competitive advantage. Outsourcing, which can result in greater profitability and competitiveness, is one of these enterprise activities [1]. Most global companies outsource their logistics activities. For example, according to Forrester Research, 54 per cent of Fortune 500 enterprises have outsourced their distribution services, 78 per cent of them have outsourced their transportation services, and 46 per cent have outsourced their manufacturing activities [2]. Thus it can be said that logistics outsourcing is important for companies. Additionally, logistics outsourcing has become an indispensable component of all enterprises because of the increased cost pressure on businesses and the globalisation of enterprise activities [3].

The execution of logistics activities by a good strategic partner will provide the following benefits: decreased costs, increased logistics performance, and a focus on their core business activities and on building virtual businesses [4]. The logistics activities of companies can be carried out by third-party logistics (3PL) providers instead of the enterprises themselves. Although 3PL providers function at locations in the supply chain between the producer and the end consumer, they are named 'third party' because they do not have their own products [5]. The services that an enterprise requires, such as freight consolidation and distribution, pro-logistics transportation, cross-docking, and storing and stock management, can be supplied by a 3PL provider [6]. Companies need to work with strategic 3PL providers to take advantage of such benefits.

Since a 3PL provider has a critical position and role in logistics tasks, working with a high-performance 3PL provider will allow logistical activities to be carried out properly. A range of quantitative and qualitative attributes, which are frequently in conflict with each other, may be involved in the procedure to select 
3PL providers; so this selection is a multi-criteria decision-making problem that includes various types of vagueness [6]. Multi-criteria decision-making methods are used to solve these types of problem, which are affected by several attributes [7]. As human preference, perception, intuition, and judgement remain uncertain and hard to gauge, methods that use crisp numbers might not always be sufficient to handle an uncertainty problem. In order to address this issue, many approaches, such as fuzzy set theory (FST), rough theory (RT), and grey theory (GT), are proposed in the literature. According to the literature, FST has been used more than GT in selecting a 3PL provider. However, GT considers the circumstance of fuzziness, and that is the key advantage of GT over FST; and GT generates satisfactory results using limited, small, and incomplete data [8-10]. Therefore, in this study a grey hybrid multi-criteria decision-making method is preferred to handle the vagueness issue in selecting a 3PL provider. This study contributes to the literature by proposing a new grey hybrid model that incorporates grey step-wise weight assessment ratio analysis (SWARA) and grey combinative distance-based assessment (CODAS) to identify the best 3PL provider.

The structure of this article is as follows. Section 2 presents a detailed literature review related to 3PL provider selection and the CODAS method. The grey SWARA and CODAS methods are elucidated in Section 3. A case study in the textile industry is related to the application of the grey hybrid model, and a comparison of the results of grey CODAS and those of grey COPRAS (complex proportional assessment) multi-criteria decision-making (MCDM) [11], grey additive ratio assessment (ARAS) [12], and grey multiattributive border approximation area comparison (MABAC) [13] is given in Section 4. Section 5 presents the discussion, followed by a brief conclusion.

\section{LITERATURE REVIEW}

\subsection{Literature review related to third-party logistics provider evaluation}

A company needs to be able to increase its competitiveness by cooperating closely with partners in the competitive global environment. A 3PL provider that helps companies to take advantage in the competitive environment is a significant outsourcing partner for such companies. 3PL providers should have professional experience in the services of transportation, warehousing, and so forth, as they mostly focus their attention on these services [14]. The selection of the right 3PL provider is a crucial issue for firms, given the increasing significance of outsourcing logistics [15].

The studies in the literature related to the selection of a 3PL provider used MCDM, artificial intelligence, statistical methods, hybrid methods, and mathematical programming [16]. Among these approaches, integrated methods are useful to determine the most important assessment criteria and to choose the best 3PL provider [16]. For instance, Zhang, Shang and Li [17] suggested an integrated model using K-means clustering, TOPSIS, and an information granulation entropy approach to choose a 3PL provider. In their study, an information granulation entropy approach was used to identify the weights of the criteria, and TOPSIS was used to rank the 3PL providers. Their integrated model considered five main assessment criteria: enterprise culture, financial performance, client relationships, improvement and compatibility, and operational capabilities. Falsini et al. [18] proposed a hybrid method integrating the analytic hierarchy process (AHP), linear programming, and data envelopment analysis to assess and choose the best 3PL provider in Italy. They took into account seven main criteria: speed of service, environmental safeguards, equipment, costs, flexibility, operators' safety, and quality and reliability. They also validated their model in three sectors: perishable products, industry and defence, and consumer goods. Kabir [19] integrated the fuzzy analytic hierarchy process (FAHP) and fuzzy TOPSIS methods to assess and select a suitable 3PL provider. Wong [20] suggested a decision support system consisting of pre-emptive fuzzy integer goal programming and the fuzzy analytic network process (FANP) to identify the best 3PL provider in a global supply chain. In another study, Perçin and Min [21] proposed an integrated approach using zero-one goal programming, quality function deployment, and fuzzy linear regression to identify the best 3PL provider for a company in the automobile industry. Hsu et al. [22] suggested a hybrid model using the analytic network process (ANP), Decision Making Trial and Evaluation Laboratory (DEMATEL), and grey relation to identify the best outsourcing partner for a Taiwanese firm. Akman and Baynal [2] combined FAHP and fuzzy TOPSIS to determine the best 3PL provider among seven alternatives for a Turkish tyre company. Hwang and Shen [23] proposed a non-additive fuzzy integral to identify criteria weights and select the best 3PL provider. The six main criteria they considered were information technology, cost, service, performance, quality assurance, and intangibles. Sharma and Kumar [24] integrated quality function deployment and Taguchi loss function to choose the optimal 3PL provider for an Indian ball-bearing manufacturing firm. Yayla et al. [25] developed a model consisting of FAHP and fuzzy TOPSIS to determine the most appropriate 3PL provider for a Turkish confectionery firm. The three criteria they considered were service quality, developing sustainable relationships, and continuous improvement. Sahu et al. [26] developed a model 
based on interval-valued fuzzy numbers to assess and choose 3PL providers for an automobile part manufacturing enterprise in India. Govindan et al. [6] proposed a grey DEMATEL model to develop the selection criteria for a 3PL provider for an automobile manufacturing firm in Iran. Keshavarz Ghorabaee et al. [3] developed an integrated model based on interval type-2 fuzzy, including weighted aggregated sum product assessment (WASPAS) and criteria importance through inter-criteria correlation (CRITIC) to assess $3 \mathrm{PL}$ providers. Jung [27] proposed an FAHP method to solve the 3PL provider assessment problem taking into account social sustainability. Raut et al. [1] combined data envelopment analysis and ANP to assess and select 3PL providers. Ji et al. [28] developed a model based on single valued neutrosophic sets with Bonferroni mean operator to identify the best 3PL provider. Karbassi Yazdi et al. [29] the Delphi method, the entropy method, and an area-based evaluation method for ranking to select 3PL providers for the Iranian automobile industry. Chen et al. [30] developed a model using extended regret theory and fuzzy axiomatic design to select the best logistics provider in an omni-channel environment. Singh et al. [31] integrated FAHP and fuzzy TOPSIS to determine the best 3PL provider for an Indian food manufacturing company. Sremac et al. [32] integrated rough SWARA, rough WASPAS, and rough Dombi aggregator to determine the best 3PL provider for the Serbian chemical industry. Ecer [16] integrated evaluation based on distance from average solution (EDAS) and FAHP to choose the best 3PL provider for a Turkish marble company. Pamucar [15] combined the best-worst method, MABAC, and WASPAS based on interval rough numbers to assess $3 \mathrm{PL}$ providers.

\subsection{Literature review related to CODAS}

The CODAS method (developed by Keshavarz Ghorabaee [33]), which is a kind of MCDM method, has been used in the literature to rank alternatives by using two distances approaches (Euclidean and Taxicab). Many studies have used this technique and its types to address MCDM problems. Table 1 summarises the studies that have used CODAS and its types .

Table 1: Literature related to CODAS

\begin{tabular}{|c|c|}
\hline References & Study abstract \\
\hline Keshavarz Ghorabaee [34] & $\begin{array}{l}\text { Suggested fuzzy CODAS to assess and select market segment for a } \\
\text { shoe company. }\end{array}$ \\
\hline Panchal et al. [35] & $\begin{array}{l}\text { Integrated fuzzy AHP and fuzzy CODAS to select the best } \\
\text { maintenance strategy for an Indian urea fertilizer business. }\end{array}$ \\
\hline Bolturk and Kahraman [36] & $\begin{array}{c}\text { Proposed interval-valued intuitionistic fuzzy CODAS to select the } \\
\text { best wave energy facility location. }\end{array}$ \\
\hline Bolturk [37] & $\begin{array}{l}\text { Suggested Pythagorean fuzzy CODAS to solve the selection of } \\
\text { supplier problem. }\end{array}$ \\
\hline Badi et al. [38] & $\begin{array}{l}\text { Proposed CODAS to choose the best supplier for a Libyan steelmaking } \\
\text { company. }\end{array}$ \\
\hline Pamučar et al. [39] & $\begin{array}{l}\text { Suggested a linguistic neutrosophic CODAS method to choose the } \\
\text { optimal power-generation technology located in Libya. }\end{array}$ \\
\hline Mathew and Sahu [40] & $\begin{array}{l}\text { Proposed the CODAS, WASPAS, EDAS, and multi-objective } \\
\text { optimisation on the basis of ratio analysis (MOORA) methods to solve } \\
\text { the selection of material handling equipment problems. }\end{array}$ \\
\hline Ren [41] & $\begin{array}{c}\text { Integrated interval AHP and intuitionistic fuzzy CODAS to rank } \\
\text { alternatives for energy storage technologies. }\end{array}$ \\
\hline Dahooei et al. [42] & $\begin{array}{l}\text { Suggested CODAS with interval-valued intuitionistic fuzzy sets to } \\
\text { assess the business intelligence of enterprise systems. }\end{array}$ \\
\hline Peng and Garg [43] & $\begin{array}{c}\text { Combined weighted distance-based approximation, CODAS, and } \\
\text { similarity measure to solve the problem of mines' emergency } \\
\text { decision-making in an interval-valued fuzzy soft decision } \\
\text { environment. }\end{array}$ \\
\hline Yeni and Özçelik [44] & $\begin{array}{c}\text { Proposed interval-valued Atanassov intuitionistic fuzzy CODAS to } \\
\text { solve a personnel selection problem for a company. }\end{array}$ \\
\hline Karașan et al. [45] & $\begin{array}{c}\text { Suggested interval-valued neutrosophic CODAS to select the location } \\
\text { for a wind energy plant in Turkey. }\end{array}$ \\
\hline Laha and Biswas [46] & $\begin{array}{c}\text { Combined the entropy and CODAS methods to analyse the } \\
\text { performance of banks in India. }\end{array}$ \\
\hline
\end{tabular}

As can be seen from the table above, no study has used the grey SWARA and the grey CODAS (CODAS-G) methods together to solve any problem. This study will fill this gap in the literature. The next section describes the methods applied in this study. 
This section consists of three sub-sections: arithmetic operations for grey numbers, grey SWARA, and CODAS-G.

\subsection{Arithmetic operations for grey numbers}

Suppose that $\otimes F=[F ; \bar{F}]$ and $\otimes Y=[\underline{Y} ; \bar{Y}]$ denotes two non-negative grey numbers and $p$ is a crisp and positive natural number. Arithmetic operations for these numbers are indicated as follows [8]:

$$
\begin{gathered}
\otimes F+\otimes Y=[\underline{F}+\underline{Y} ; \bar{F}+\bar{Y}] \\
\otimes F-\otimes Y=[\underline{F}-\bar{Y} ; \bar{F}-\underline{Y}] \\
\otimes F \times \otimes Y=[\min \{\underline{F Y}, \bar{F} \bar{Y}, \bar{F}, \bar{Y}, \overline{F Y}\} ; \max \{\underline{F Y}, \underline{F} \bar{Y}, \bar{F}, \bar{Y}, \overline{F Y}\}] \\
\otimes F / \otimes Y=[\min \{\underline{F} / \underline{Y}, \underline{F} / \bar{Y}, \bar{F} / \underline{Y}, \bar{F} / \bar{Y}\} ; \max \{\underline{F} / \underline{Y}, \underline{F} / \bar{Y}, \bar{F} / \underline{Y}, \bar{F}\}]
\end{gathered}
$$

For Euclidian and Taxicab distances, equations 5 and 6 respectively are used.

$$
\begin{gathered}
(\otimes F-\otimes Y)^{p}=\left[(\underline{F}-\underline{Y})^{p} ;(\bar{F}-\bar{Y})^{p}\right] p \in N^{+} \\
|\otimes F-\otimes Y|=[|\underline{F}-\underline{Y}| ;|\bar{F}-\bar{Y}|]
\end{gathered}
$$

\subsection{Grey SWARA}

In this study, the grey SWARA [47] method is used to determine the weights of defined criteria. This method is an extension of traditional SWARA [48]. The steps of grey SWARA are explained as follows:

Step 1.1. Defined criteria are ordered by decision-makers in descending expected importance.

Step 1.2. The relative importance of the $j$ th criterion is identified by comparing it with the $j-1$ th criterion. This process continues until the last criterion. When decision-makers compare two criteria, they use the linguistic comparison terms shown in Table 2 to compute $\otimes a_{j}$ (the grey comparative importance of the average value).

\section{Table 2: Linguistic comparison terms and grey numbers}

\begin{tabular}{|c|c|}
\hline $\begin{array}{c}\text { Linguistic comparison } \\
\text { terms }\end{array}$ & Grey numbers \\
\hline Equally significant & {$[1,1]$} \\
\hline Moderately significant & {$[1,3]$} \\
\hline Strongly significant & {$[3,5]$} \\
\hline Very strongly significant & {$[5,7]$} \\
\hline Extremely significant & {$[7,9]$} \\
\hline
\end{tabular}

Step 1.3. The grey coefficient $\left(\otimes b_{j}\right)$ is calculated by using equation 7 .

$$
\otimes b_{j}= \begin{cases}{[1 ; 1]} & j=1 \\ \otimes a_{j}+[1 ; 1] & j>1\end{cases}
$$

Step 1.4. The recalculated grey weight for each criterion, $\otimes t_{j}$, is computed with equation 8 .

$$
\otimes t_{j}= \begin{cases}{[1 ; 1]} & j=1 \\ \frac{\otimes y_{j-1}}{\otimes b_{j}} & j>1\end{cases}
$$

Step 1.5. The grey weight for each criterion is computed with equation 9 .

$$
\otimes w_{j}=\frac{\otimes t_{j}}{\sum_{j=1}^{n} \otimes t_{j}}
$$

$\otimes w_{j}=\left[\underline{w}_{j} ; \bar{w}_{j}\right]$ denotes the grey weight of the $j$ th criterion. After all decision-makers have identified the grey weights, the arithmetic mean is used to consolidate these weights, which are transferred into CODASG. 


\subsection{CODAS-G}

In this study, the grey extension of CODAS is proposed to select the 3PL provider. The steps of CODAS-G are explained as follows:

Step 2.1. Decision-makers assign the terms in Table 3 with respect to the performance of a 3PL provider, and these scores are aggregated by using the arithmetic mean to structure the grey decision matrix $(\otimes Z)$ as follows:

$$
\otimes Z=\left[\otimes z_{i j}\right]_{n \times m}=\left[\begin{array}{cccc}
\otimes z_{11} & \otimes z_{12} & \cdots & \otimes z_{1 m} \\
\otimes z_{21} & \otimes z_{22} & \cdots & \otimes z_{2 m} \\
\vdots & \vdots & \vdots & \vdots \\
\otimes z_{n 1} & \otimes z_{n 2} & \cdots & \otimes z_{2 m}
\end{array}\right]
$$

where $\otimes z_{i j}$ is the grey performance value of the $i$ th $3 \mathrm{PL}$ provider on the $j$ th criterion.

Table 3: Linguistic terms and grey numbers

\begin{tabular}{|c|c|}
\hline Linguistic terms & Grey numbers \\
\hline Very high & {$[9,10]$} \\
\hline High & {$[7,9]$} \\
\hline Medium & {$[5,7]$} \\
\hline Low & {$[3,5]$} \\
\hline Very low & {$[1,3]$} \\
\hline
\end{tabular}

Step 2.2. Grey normalised decision matrix is calculated by using equation 11 .

$$
\otimes u_{i j}= \begin{cases}\frac{\otimes z_{i j}}{\max _{i} \otimes z_{i j}}=\left[\frac{\underline{z}_{i j}}{\max _{i} \bar{z}_{i j}} ; \frac{\bar{z}_{i j}}{\max _{i} \bar{z}_{i j}}\right], & \text { if } j \in C_{b} \\ \frac{\min _{i} \otimes z_{i j}}{\otimes z_{i j}}=\left[\frac{\min _{i} \underline{z}_{i j}}{\bar{z}_{i j}} ; \frac{\min _{i} \underline{Z}_{i j}}{\underline{z}_{i j}}\right], & \text { if } j \in C_{n b}\end{cases}
$$

where $C_{b}$ and $C_{n b}$ indicate the sets of beneficial and non-beneficial criteria respectively. In equation 11 , $\otimes u_{i j}$ denotes a grey normalised value of $\otimes z_{i j}$.

Step 2.3. Grey weighted normalised values are computed by using equation 12 .

$$
\otimes f_{i j}=\otimes w_{j} \otimes u_{i j}
$$

Step 2.4. Grey negative-ideal solution is determined as follows:

$$
\begin{aligned}
& \otimes n s=\left[\otimes n s_{j}\right]_{1 \times m} \\
& \otimes n s_{j}=m i n_{i} \otimes f_{i j}
\end{aligned}
$$

Step 2.5. $\otimes E C D_{i}$ and $\otimes T X D_{i}$ distances of 3PL providers from the grey negative-ideal solution are computed by using equations 15 and 16.

$$
\begin{gathered}
\otimes E C D_{i}=\sqrt{\sum_{j=1}^{m}\left(\otimes f_{i j}-\otimes n s_{j}\right)^{2}} \\
\otimes T X D_{i}=\sum_{j=1}^{m}\left|\otimes f_{i j}-\otimes n s_{j}\right|
\end{gathered}
$$

Step 2.6. Equation 17 is used for $\otimes E C D_{i}$ conversion into crisp $E C D_{i}$, and equation 18 is used for $\otimes T X D_{i}$ conversion into crisp $T X D_{i}$. In equations 17 and $18, \lambda$ is set as 0.5 for this study.

$$
\begin{array}{ll}
E C D_{i}=(1-\lambda) \times \underline{E C D_{i}}+\lambda \times \overline{E C D}_{i} & \lambda \in\{0,1\} \\
T X D_{i}=(1-\lambda) \times{\underline{T X D_{i}}}_{i}+\lambda \times \overline{T X D}_{i} & \lambda \in\{0,1\}
\end{array}
$$

Step 2.7. The relative assessment matrix $(B a)$ shown in equation 19 is established by using equation 20 .

$$
\begin{gathered}
B a=\left[g_{i k}\right]_{n \times n} \\
g_{i k}=\left(E C D_{i}-E C D_{k}\right)+\left(\delta\left(E C D_{i}-E C D_{k}\right) \times\left(T X D_{i}-T X D_{k}\right)\right)
\end{gathered}
$$

$\delta$, indicating threshold function, can be shown as: 


$$
\delta(x)= \begin{cases}1 & \text { if }|x| \geq \rho \\ 0 & \text { if }|x|<\rho\end{cases}
$$

$\rho$ denotes the function's threshold parameter, and the decision-maker can set this value between 0.01 and 0.05 . In this study, this value is set at 0.02 .

Step 2.8.The final score $\left(G_{i}\right)$ for each $3 \mathrm{PL}$ provider can be computed as:

$$
G_{i}=\sum_{k=1}^{n} g_{i k}
$$

The 3PL provider that has the highest $G_{i}$ is identified as the best 3PL provider.

The next section illustrates the application of the proposed model.

\section{APPLICATION}

The grey integrated model was applied to a Turkish textile firm that manufactures fabric The company wanted to cooperate with a $3 \mathrm{PL}$ provider to deliver its products to global markets. For the evaluation process, an expert team consisting of this firm's top management (five people) was formed, and asked to decide on the criteria used in the literature. The expert team took a joint decision to use seven criteria in the selection process: cost $(C)$, delivery $(D)$, quality $(Q)$, services $(S)$, flexibility $(F L)$, reputation $(R)$, and financial position (FP).

First, the steps of grey SWARA were applied to derive grey weights. Table 4 illustrates the results of the grey SWARA for Expert 1.

Table 4: The results of grey SWARA for Expert 1

\begin{tabular}{|c|c|c|c|c|}
\hline Criteria & $\otimes \boldsymbol{a}_{\boldsymbol{j}}$ & $\otimes \boldsymbol{b}_{\boldsymbol{j}}$ & $\otimes \boldsymbol{t}_{\boldsymbol{j}}$ & $\otimes \boldsymbol{w}_{\boldsymbol{j}}$ \\
\hline $\mathrm{C}$ & & {$[1,1]$} & {$[1,1]$} & {$[0.521,0.601]$} \\
\hline $\mathrm{D}$ & {$[1,1]$} & {$[2,2]$} & {$[0.5,0.5]$} & {$[0.261,0.301]$} \\
\hline $\mathrm{Q}$ & {$[1,3]$} & {$[2,4]$} & {$[0.125,0.250]$} & {$[0.065,0.150]$} \\
\hline $\mathrm{S}$ & {$[1,3]$} & {$[2,4]$} & {$[0.031,0.125]$} & {$[0.016,0.075]$} \\
\hline $\mathrm{R}$ & {$[3,5]$} & {$[4,6]$} & {$[0.005,0.031]$} & {$[0.003,0.019]$} \\
\hline $\mathrm{FS}$ & {$[3,5]$} & {$[4,6]$} & {$[0.001,0.008]$} & {$[0.001,0.005]$} \\
\hline $\mathrm{FL}$ & {$[1,1]$} & {$[2,2]$} & {$[0.001,0.004]$} & {$[0.001,0.002]$} \\
\hline
\end{tabular}

The grey weights of the criteria were also calculated for the other experts using the grey SWARA method. After this process, all the grey weights of the criteria were combined using the arithmetic mean. Table 5 presents the combined grey weights.

Table 5: The combined grey weights

\begin{tabular}{|c|c|}
\hline Criteria & $\otimes \boldsymbol{w}_{j}$ \\
\hline C & {$[0.392,0.454]$} \\
\hline D & {$[0.374,0.428]$} \\
\hline Q & {$[0.073,0.154]$} \\
\hline S & {$[0.048,0.077]$} \\
\hline R & {$[0.002,0.007]$} \\
\hline FL & {$[0.002,0.005]$} \\
\hline FS & {$[0.001,0.004]$} \\
\hline
\end{tabular}

After identifying the grey weights, the grey decision matrix $(\otimes Z)$ was structured by using the arithmetic mean to aggregate the preferences of the decision-makers. Table 6 gives the grey decision matrix $(\otimes Z)$. 
Table 6: The grey decision matrix $(\otimes Z)$

\begin{tabular}{|c|c|c|c|c|}
\hline $\mathrm{Alternatives}_{\text {Altiteria }}^{\text {Crita }}$ & C & D & Q & $\mathrm{s}$ \\
\hline 3PL 1 & {$[3.8,5.8]$} & {$[5.4,7.4]$} & {$[4.6,6.6]$} & {$[5.4,7.4]$} \\
\hline 3PL 2 & {$[4.6,6.6]$} & {$[6.2,8.2]$} & {$[5.8,7.8]$} & {$[5.4,7.4]$} \\
\hline $3 \mathrm{PL} 3$ & {$[5.8,7.8]$} & {$[5.8,7.8]$} & {$[4.6,6.6]$} & {$[6.6,8.6]$} \\
\hline $3 \mathrm{PL} 4$ & {$[5,7]$} & {$[5.4,7.4]$} & {$[5.4,7.4]$} & {$[5.8,7.8]$} \\
\hline Alternatives & FL & \multicolumn{2}{|c|}{$\mathbf{R}$} & FS \\
\hline 3PL 1 & {$[2.6,4.6]$} & \multicolumn{2}{|c|}{$[6.2,8.2]$} & {$[4.6,6.6]$} \\
\hline $3 \mathrm{PL} 2$ & {$[2.2,4.2]$} & \multicolumn{2}{|c|}{$[6.2,8.2]$} & {$[4.2,6.2]$} \\
\hline $3 \mathrm{PL} 3$ & {$[2.6,4.6]$} & \multirow{2}{*}{\multicolumn{2}{|c|}{$[7,8.8]$}} & {$[4.6,6.6]$} \\
\hline $3 \mathrm{PL} 4$ & {$[2.6,4.6]$} & & & {$[4.6,6.6]$} \\
\hline
\end{tabular}

Equation 11 was used to determine the grey normalised decision matrix, shown in Table 7.

Table 7: The grey normalised decision matrix

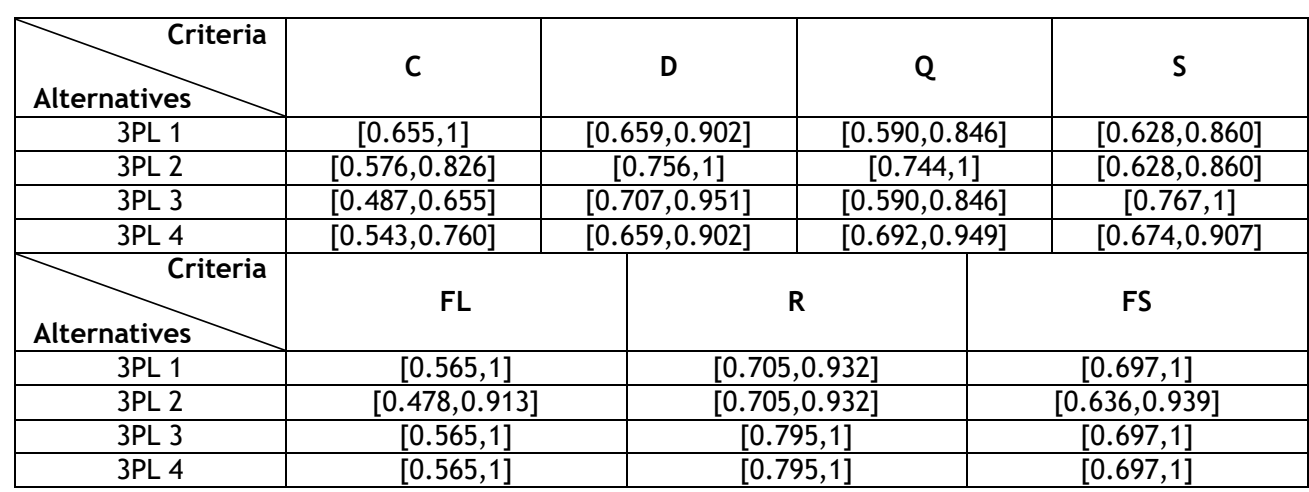

The grey weights of the criteria were multiplied by the grey normalised values to obtain the grey weighted normalised values, using Equation 12. Equation 14 was used to determine the grey negative-ideal solution. Table 8 presents the grey weighted normalised values and the grey negative-ideal solution.

Table 8: The grey weighted normalised values and the grey negative-ideal solution

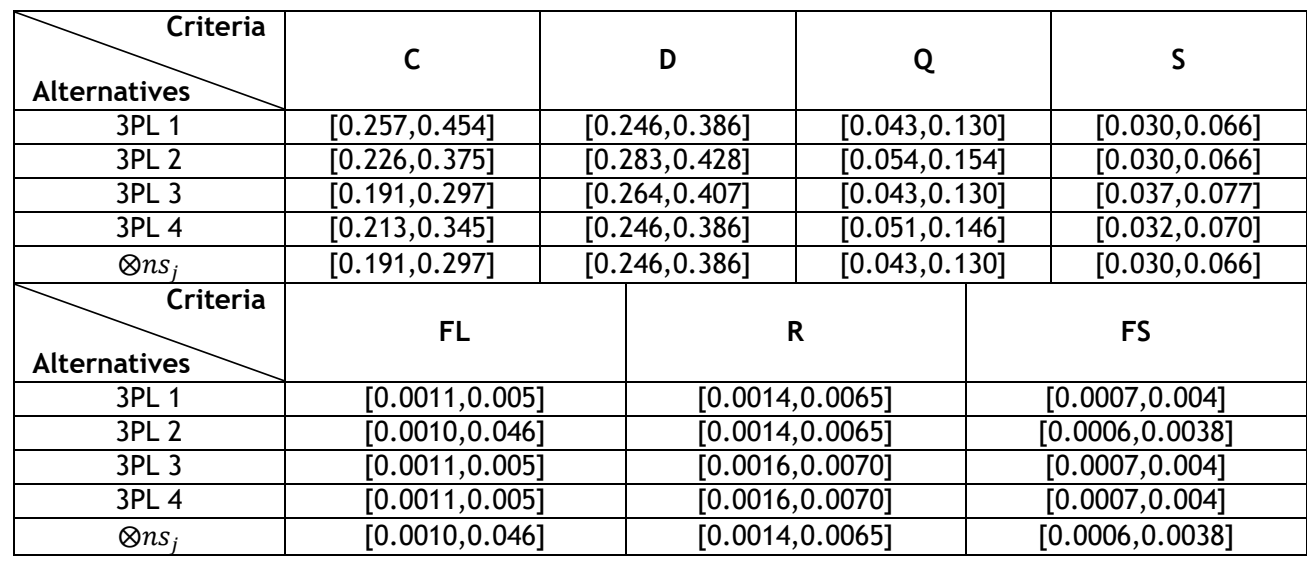

$\otimes E C D_{i}$ and $\otimes T X D_{i}$ distances were computed by using equations 15 and 16 respectively. These grey values were converted into crisp $E C D_{i}$ and $T X D_{i}$ by using equations 17 and 18 respectively. Table 9 illustrates these values for each $3 \mathrm{PL}$ provider. 
Table 9: The values of $\otimes E C D_{i}, \otimes T X D_{i}, E C D_{i}$ and $T X D_{i}$

\begin{tabular}{|c|c|c|c|c|}
\hline Results & $\otimes \boldsymbol{E C D}_{\boldsymbol{i}}$ & $\boldsymbol{\otimes} \boldsymbol{T} \boldsymbol{X} \boldsymbol{D}_{\boldsymbol{i}}$ & $\boldsymbol{E} \boldsymbol{C \boldsymbol { D } _ { \boldsymbol { i } }}$ & $\boldsymbol{T X}_{\boldsymbol{i}}$ \\
\hline Alternatives & {$[0.066,0.157]$} & {$[0.0662,0.1576]$} & 0.1115 & 0.1119 \\
\hline 3PL 1 & {$[0.0521,0.0918]$} & {$[0.083,0.144]$} & 0.0720 & 0.1135 \\
\hline 3PL 2 & {$[0.0193,0.0237]$} & {$[0.0254,0.0331]$} & 0.0215 & 0.0293 \\
\hline 3PL 3 & {$[0.0235,0.0508]$} & {$[0.0324,0.0691]$} & 0.0372 & 0.0508 \\
\hline
\end{tabular}

In the final step, the relative assessment matrix $(B a)$ was generated, and the final score for each 3PL provider was calculated. Table 10 presents this matrix and the final scores $\left(G_{i}\right)$.

Table 10: The relative assessment matrix $(B a)$ and final scores $\left(G_{i}\right)$

\begin{tabular}{|c|c|c|c|c|c|c|}
\hline Results & 3PL 1 & 3PL 2 & 3PL 3 & 3PL 4 & $\boldsymbol{G}_{\boldsymbol{i}}$ & Ranking \\
Alternatives & & & & & & \\
\hline 3PL 1 & 0.00000 & 0.03790 & 0.17260 & 0.13540 & 0.34590 & 1 \\
\hline 3PL 2 & -0.03790 & 0.00000 & 0.13470 & 0.09750 & 0.19430 & 2 \\
\hline 3PL 3 & -0.17260 & -0.13470 & 0.00000 & -0.01570 & -0.32300 & 4 \\
\hline 3PL 4 & -0.13540 & -0.09750 & 0.01570 & 0.00000 & -0.21720 & 3 \\
\hline
\end{tabular}

According to Table 10, the 3PL providers were sequenced as follows: $3 \mathrm{PL} 1>3 \mathrm{PL2}>3 \mathrm{PL} 4>3 \mathrm{PL} 3$. The results of the grey CODAS were compared with the results from other grey methods (grey COPRAS, grey ARAS, and grey MABAC). Table 11 gives the comparison of the grey methods.

Table 11: Comparison of grey methods

\begin{tabular}{|c|c|c|c|c|}
\hline Rlternatives & $\begin{array}{c}\text { Results } \\
\text { Final } \\
\text { scores }\end{array}$ & $\begin{array}{c}\text { Grey } \\
\text { SWARA - } \\
\text { grey } \\
\text { CODAS }\end{array}$ & Final & $\begin{array}{c}\text { Grey } \\
\text { scores } \\
\text { SWARA - } \\
\text { grey } \\
\text { COPRAS }\end{array}$ \\
\hline 3PL 1 & 0.34590 & 1 & 1 & 1 \\
\hline 3PL 2 & 0.19430 & 2 & 0.9941 & 2 \\
\hline 3PL 3 & -0.32300 & 4 & 0.8941 & 4 \\
\hline 3PL 4 & -0.21720 & 3 & 0.9188 & 3 \\
\hline Results & $\begin{array}{c}\text { Final } \\
\text { scores }\end{array}$ & $\begin{array}{c}\text { Grey } \\
\text { SWARA - } \\
\text { grey ARAS }\end{array}$ & $\begin{array}{c}\text { Final } \\
\text { scores }\end{array}$ & $\begin{array}{c}\text { Grey } \\
\text { SWARA - } \\
\text { grey } \\
\text { MABAC }\end{array}$ \\
\hline 3PL 1 & 0.9703 & 1 & 0.04417 & 1 \\
\hline 3PL 2 & 0.9576 & 2 & 0.04192 & 2 \\
\hline 3PL 3 & 0.8559 & 4 & -0.04713 & 4 \\
\hline 3PL 4 & 0.8856 & 3 & -0.02269 & 3 \\
\hline
\end{tabular}

As can be seen from Table 11, the rankings of the 3PL providers did not change. This indicates that the CODAS-G method achieved accurate results.

\section{DISCUSSION}

As can be seen in the literature review section of this paper, the AHP, fuzzy AHP, and ANP methods have been used many times in the literature. The grey SWARA method has a less complex structure than these other methods, and can obtain criterion weights with less data. In addition, the rough SWARA method has been used in some studies. Although most of the steps in the rough SWARA method (except for the first) are similar to the grey SWARA method, the first step of the rough SWARA method makes the method complicated. In particular, combining the values assigned by decision-makers makes the rough SWARA method more complex than the grey SWARA method. For all these reasons, the grey SWARA method was preferred in this study to find the weights of the criteria.

TOPSIS, EDAS, MABAC, WASPAS, and their fuzzy and rough versions were used in most of the studies in the literature. Since the grey CODAS method uses two different distance approaches (Euclidean and Taxicab), it can be said that it achieves more detailed and rigorous results than the other methods. In addition, the grey CODAS can reach a solution with a small and limited dataset. Here, less data means that the smallest 
and largest values of any criterion re sufficient for the grey CODAS method to start its analysis and to achieve results.

The proposed model can be easily used in circumstances with little, limited, or incomplete data and high uncertainty. The fact that the process steps of the grey SWARA method are fewer and are not complicated helps to reach the criterion weights quickly; and the grey CODAS method helps to maintain rigour and achieve accurate results, thanks to the two-distance approach it uses.

To test the validity of the proposed model for businesses, a short survey was conducted with five managers in the textile company where the model was applied. Two questions were asked in the questionnaire: (1) "What is the performance of the proposed model in reaching correct results? Please rate it on a scale of 1 (very bad) to 10 (very good)"; and (2) "Do you think the proposed model is feasible for businesses? Please rate it on a scale of 1 (definitely no) to 10 (definitely yes)". Table 12 presents the results of the questionnaire.

Table 12: Results of questionnaire

\begin{tabular}{|c|c|c|c|c|c|c|}
\hline Experts & Expert & Expert & Expert & Expert & Expert & Average \\
Questions & $\mathbf{1}$ & $\mathbf{2}$ & $\mathbf{3}$ & $\mathbf{4}$ & $\mathbf{5}$ & \\
\hline Question 1 & 8 & 8 & 7 & 9 & 9 & 8.2 \\
\hline Question 2 & 7 & 8 & 8 & 10 & 9 & 8.4 \\
\hline
\end{tabular}

As can be seen from Table 12, the average score given to the first question (on the performance of the proposed model) was 8.2, while the average score given to the second question (on the feasibility of the proposed model) was 8.4. Since both scores were high, the performance of the proposed model according to the managers was very high, and the proposed model was found to be feasible for this firm.

\section{CONCLUSION}

Firms need to cooperate with good 3PL providers to gain advantages from the relationships, such as reduced costs, improved logistics performance, the ability to concentrate on their core business activities, and so on. Therefore the selection of a 3PL provider has strategic importance for companies. Solving the 3PL provider selection problem requires multi-criteria decision-making methods, since this selection process contains both qualitative and quantitative criteria that may also include uncertain data. As multi-criteria decision-making methods with crisp numbers may not adequately handle uncertain data, many approaches - such as FST, GT, and RT - have been proposed in the literature. As GT considers the circumstance of fuzziness and generates satisfactory results even with small, limited, and incomplete data, this study used GT to solve the 3PL provider selection problem. In this study, grey SWARA and grey CODAS were applied to a Turkish textile company. According to the results of the proposed model, the 3PL providers were ordered as follows: 3PL1 > 3PL2 > 3PL4 > 3PL3. The results of the grey CODAS were also compared with those from other grey methods (grey COPRAS, grey ARAS, and grey MABAC). The comparison showed that the grey CODAS achieved the same results as the other grey methods, proving that the method's results were correct. In addition, in order to test the validity of the proposed model for businesses, a short survey was conducted with five managers in the textile company where the model was applied. They were asked two questions in a questionnaire, and the results showed that the the performance of the proposed model was very high and that the proposed model was feasible for use in this firm.

This study contributes to the literature by proposing a new grey hybrid model using grey SWARA and grey CODAS to identify the best $3 \mathrm{PL}$ provider. Future research could use grey CODAS to solve different multicriteria decision-making methods.

\section{REFERENCES}

[1] Raut, R., Kharat, M., Kamble, S., \& Kumar, C. S. 2018. Sustainable evaluation and selection of potential thirdparty logistics (3PL) providers: An integrated MCDM approach. Benchmarking: An International Journal, 25(1), pp. 76-97.

[2] Akman, G., \& Baynal, K. 2014. Logistics service provider selection through an integrated fuzzy multicriteria decision making approach. Journal of Industrial Engineering, Article ID:794918, 16 pages.

[3] Keshavarz Ghorabaee, M., Amiri, M., Kazimieras Zavadskas, E., \& Antuchevičienè, J. 2017. Assessment of thirdparty logistics providers using a CRITIC-WASPAS approach with interval type-2 fuzzy sets. Transport, 32(1), pp. 6678. 
[4] Aguezzoul, A. 2014. Third-party logistics selection problem: A literature review on criteria and methods. Omega, 49, pp. 69-78.

[5] Tombido, L. L., Louw, L., \& Van Eeden, J. 2018. A systematic review of 3PLs' entry into reverse logistics. South African Journal of Industrial Engineering, 29(3), pp. 235-260.

[6] Govindan, K., Khodaverdi, R., \& Vafadarnikjoo, A. 2016. A grey DEMATEL approach to develop third-party logistics provider selection criteria. Industrial Management \& Data Systems, 116(4), pp. 690-722.

[7] Yildiz, A., \& Ergul, E. U. 2015. A two-phased multi-criteria decision-making approach for selecting the best smartphone. South African Journal of Industrial Engineering, 26(3), pp. 194-215.

[8] Liu, S., \& Lin, Y. 2006. Grey information: Theory and practical applications. London, Springer Science \& Business Media.

[9] Bai, C., \& Sarkis, J. 2010. Integrating sustainability into supplier selection with grey system and rough set methodologies. International Journal of Production Economics, 124(1), pp. 252-264.

[10] Xia, X., Govindan, K., \& Zhu, Q. 2015. Analyzing internal barriers for automotive parts remanufacturers in China using grey-DEMATEL approach. Journal of Cleaner Production, 87, pp. 811-825.

[11] Zavadskas, E. K., Kaklauskas, A., Turskis, Z., \& Tamošaitiene, J. 2008. Selection of the effective dwelling house walls by applying attributes values determined at intervals. Journal of Civil Engineering and Management, 14(2), pp. 85-93.

[12] Turskis, Z., \& Zavadskas, E. K. 2010. A novel method for multiple criteria analysis: Grey additive ratio assessment (ARAS-G) method. Informatica, 21(4), pp. 597-610.

[13] Debnath, A., Roy, J., Kar, S., Zavadskas, E., \& Antucheviciene, J. 2017. A hybrid MCDM approach for strategic project portfolio selection of agro by-products. Sustainability, 9(8), 1302.

[14] Chen, K. Y., \& Wu, W. T. 2011. Applying analytic network process in logistics service provider selection: A case study of the industry investing in Southeast Asia. International Journal of Electronic Business Management, 9(1), pp. 24-36.

[15] Pamucar, D., Chatterjee, K., \& Zavadskas, E. K. 2018. Assessment of third-party logistics provider using multicriteria decision-making approach based on interval rough numbers. Computers \& Industrial Engineering, 127, pp. 383-407.

[16] Ecer, F. 2018. Third-party logistics (3PLs) provider selection via fuzzy AHP and EDAS integrated model. Technological and Economic Development of Economy, 24(2), pp. 615-634.

[17] Zhang, G., Shang, J., \& Li, W. 2012. An information granulation entropy-based model for third-party logistics providers evaluation. International Journal of Production Research, 50(1), pp. 177-190.

[18] Falsini, D., Fondi, F., \& Schiraldi, M. M. 2012. A logistics provider evaluation and selection methodology based on AHP, DEA and linear programming integration. International Journal of Production Research, 50(17), pp. 48224829.

[19] Kabir, G. 2012. Third party logistic service provider selection using fuzzy AHP and TOPSIS method. International Journal for Quality Research, 6(1), pp. 71-79.

[20] Wong, J. T. 2012. DSS for 3PL provider selection in global supply chain: Combining the multi-objective optimization model with experts' opinions. Journal of Intelligent Manufacturing, 23(3), pp. 599-614.

[21] Perçin, S., \& Min, H. 2013. A hybrid quality function deployment and fuzzy decision-making methodology for the optimal selection of third-party logistics service providers. International Journal of Logistics Research and Applications, 16(5), pp. 380-397.

[22] Hsu, C. C., Liou, J. J., \& Chuang, Y. C. 2013. Integrating DANP and modified grey relation theory for the selection of an outsourcing provider. Expert Systems with Applications, 40(6), pp. 2297-2304.

[23] Hwang, B. N., \& Shen, Y. C. 2015. Decision making for third party logistics supplier selection in semiconductor manufacturing industry: A nonadditive fuzzy integral approach. Mathematical Problems in Engineering, Article ID: 918602.

[24] Sharma, S. K., \& Kumar, V. 2015. Optimal selection of third-party logistics service providers using quality function deployment and Taguchi loss function. Benchmarking: An International Journal, 22(7), pp. 1281-1300.

[25] Yayla, A. Y., Oztekin, A., Gumus, A. T., \& Gunasekaran, A. 2015. A hybrid data analytic methodology for 3PL transportation provider evaluation using fuzzy multi-criteria decision making. International Journal of Production Research, 53(20), pp. 6097-6113.

[26] Sahu, N. K., Datta, S., \& Mahapatra, S. S. 2015. Fuzzy based appraisement module for 3PL evaluation and selection. Benchmarking: An International Journal, 22(3), pp. 354-392.

[27] Jung, H. 2017. Evaluation of third party logistics providers considering social sustainability. Sustainability, 9(5), 777

[28] Ji, P., Wang, J. Q., \& Zhang, H. Y. 2018. Frank prioritized Bonferroni mean operator with single-valued neutrosophic sets and its application in selecting third-party logistics providers. Neural Computing and Applications, 30(3), pp. 799-823.

[29] Karbassi Yazdi, A., Hanne, T., Osorio Gómez, J. C., \& García Alcaraz, J. L. 2018. Finding the best third-party logistics in the automobile industry: A hybrid approach. Mathematical Problems in Engineering, Article ID: 5251261, 19 pages.

[30] Chen, W., Goh, M., \& Zou, Y. 2018. Logistics provider selection for omni-channel environment with fuzzy axiomatic design and extended regret theory. Applied Soft Computing, 71, pp. 353-363.

[31] Singh, R. K., Gunasekaran, A., \& Kumar, P. 2018. Third party logistics (3PL) selection for cold chain management: A fuzzy AHP and fuzzy TOPSIS approach. Annals of Operations Research, 268(1-2), pp. 1-23.

[32] Sremac, S., Stević, Ž., Pamučar, D., Arsić, M., \& Matić, B. 2018. Evaluation of a third-party logistics (3PL) provider using a rough SWARA-WASPAS model based on a new rough Dombi aggregator. Symmetry, 10(8), 305 
[33] Keshavarz Ghorabaee, M., Zavadskas, E. K., Turskis, Z., \& Antucheviciene, J. 2016. A new combinative distancebased assessment (CODAS) method for multi-criteria decision-making. Economic Computation \& Economic Cybernetics Studies \& Research, 50(3), pp. 25-44.

[34] Keshavarz Ghorabaee, M., Amiri, M., Zavadskas, E. K., Hooshmand, R., \& Antuchevičienè, J. 2017. Fuzzy extension of the CODAS method for multi-criteria market segment evaluation. Journal of Business Economics and Management, 18(1), pp. 1-19.

[35] Panchal, D., Chatterjee, P., Shukla, R. K., Choudhury, T., \& Tamosaitiene, J. 2017. Integrated fuzzy AHP-CODAS framework for maintenance decision in urea fertilizer industry. Economic Computation \& Economic Cybernetics Studies \& Research, 51(3), pp. 179-196.

[36] Bolturk, E., \& Kahraman, C. 2018. Interval-valued intuitionistic fuzzy CODAS method and its application to wave energy facility location selection problem. Journal of Intelligent \& Fuzzy Systems, 35(4), pp. 4865-4877.

[37] Bolturk, E. 2018. Pythagorean fuzzy CODAS and its application to supplier selection in a manufacturing firm. Journal of Enterprise Information Management, 31(4), pp. 550-564.

[38] Badi, I., Abdulshahed, A. M., \& Shetwan, A. 2018. A case study of supplier selection for a steelmaking company in Libya by using the combinative distance-based assessment (CODAS) model. Decision Making: Applications in Management and Engineering, 1(1), pp. 1-12.

[39] Pamučar, D., Badi, I., Sanja, K., \& Obradović, R. 2018. A novel approach for the selection of power-generation technology using a linguistic neutrosophic CODAS method: A case study in Libya. Energies, 11(9), 2489

[40] Mathew, M., \& Sahu, S. 2018. Comparison of new multi-criteria decision making methods for material handling equipment selection. Management Science Letters, 8(3), pp. 139-150.

[41] Ren, J. 2018. Sustainability prioritization of energy storage technologies for promoting the development of renewable energy: A novel intuitionistic fuzzy combinative distance-based assessment approach. Renewable Energy, 121, pp. 666-676

[42] Dahooei, J. H., Zavadskas, E. K., Vanaki, A. S., Firoozfar, H. R., \& Keshavarz-Ghorabaee, M. 2018. An evaluation model of business intelligence for enterprise systems with new extension of CODAS (CODAS-IVIF). Economics and Management, 21(3), pp. 171-187.

[43] Peng, X., \& Garg, H. 2018. Algorithms for interval-valued fuzzy soft sets in emergency decision making based on WDBA and CODAS with new information measure. Computers \& Industrial Engineering, 119, pp. 439-452.

[44] Yeni, F. B., \& Özçelik, G. 2018. Interval-valued Atanassov intuitionistic fuzzy CODAS method for multi criteria group decision making problems. Group Decision and Negotiation, 28(2), pp. 433-452.

[45] Karașan, A., Boltuirk, E., \& Kahraman, C. 2019. A novel neutrosophic CODAS method: Selection among wind energy plant locations. Journal of Intelligent \& Fuzzy Systems, 36(2), pp. 1491-1504.

[46] Laha, S., \& Biswasb, S. 2018. A hybrid unsupervised learning and multi-criteria decision making approach for performance evaluation of Indian banks. Accounting, 5(4), pp. 169-184.

[47] Mavi, R. K., Zarbakhshnia, N., \& Khazraei, A. 2018. Bus rapid transit (BRT): A simulation and multi criteria decision making (MCDM) approach. Transport Policy, 72, pp. 187-197.

[48] Keršuliene, V., Zavadskas, E. K., \& Turskis, Z. 2010. Selection of rational dispute resolution method by applying new step-wise weight assessment ratio analysis (SWARA). Journal of Business Economics and Management, 11(2), pp. 243-258. 